\title{
Erratum to: Role of degenerated neuron density of dorsal root ganglion on anterior spinal artery vasospasm in subarachnoid hemorrhage: experimental study
}

\author{
Ayhan Kanat • Adem Yilmaz • Mehmet D. Aydin • \\ Murat Musluman • Sare Altas • Nesrin Gursan
}

Published online: 4 November 2010

(C) Springer-Verlag 2010

\section{Erratum to: Acta Neurochir \\ DOI 10.1007/s00701-010-0793-4}

This article contains several errors.

These errors are the authors' responsibility:

In Abstract section results:

the mean ASA volume was $1,010 \pm 450 \mathrm{~mm}^{3}$

Should read:

the mean ASA volume was $1.050 \pm 0.450 \mathrm{~mm}^{3}$

The mean volume value of ASA was $970 \pm 150 \mathrm{~mm}^{3}$

Should read:

the mean volume value of ASA was $0.970 \pm 0.150 \mathrm{~mm}^{3}$

the mean volume value of ASA was $540 \pm 90 \mathrm{~mm}^{3}$

Should read:

mean volume value of ASA was $0.540 \pm 0.90 \mathrm{~mm}^{3}$

The online version of the original article can be found at http://dx.doi. org/10.1007/s00701-010-0793-4.

\section{A. Kanat}

Medical Faculty, Department of Neurosurgery, Rize University,

Rize, Turkey

\footnotetext{
A. Yilmaz $\cdot$ M. Musluman

Department of Neurosurgery, Sisli Research and Education

Hospital,

Istanbul, Turkey

M. D. Aydin $\cdot$ S. Altas $\cdot$ N. Gursan

Erzurum, Turkey

A. Kanat $(\bowtie)$

Tophane Mahallesi, Laleli Sok, Yilmaz Apt 14/3,

53100 Merkez, Rize, Turkey

e-mail: ayhankanat@yahoo.com
}

Medical Faculty Department of Neurosurgery, Ataturk University,
In Methods and material section:

section were taken by microtome of $5 \mathrm{~mm}$ distances

Should read:

Sections were taken by microtome of 5 micrometer distances

The mean radius value of basilar arteries

Should read:

The mean radius value of ASA

ASA sections of $5 \mathrm{~mm}$ imagined

Should read:

ASA sections of 5 micrometer

The differences between the volume values of basilar arteries and neuron densities of trigeminal ganglions

Should read:

The differences between the volume values of ASA and neuron density of $\mathrm{C}_{3}$ DRG

In Results section:

The mean ASA volume was estimated as $1,010 \pm 450 \mathrm{~mm}^{3}$, Should read:

The mean ASA volume was estimated as $1.050 \pm 0.450 \mathrm{~mm}^{3}$

The mean volume value of ASA was $970 \pm 150 \mathrm{~mm}^{3}$,

Should read:

The mean volume value of ASA was $0.970 \pm 0.150 \mathrm{~mm}^{3}$

the mean volume values of ASA was $540 \pm 90 \mathrm{~mm}^{3}$,

Should read:

mean volume value of ASA was $0.540 \pm 0.90 \mathrm{~mm}^{3}$

Table 1 should read:

LINE-1: ASA VOLUME $\left(\mathrm{mm}^{3}\right) \quad 1.050 \pm 0.4500 .970 \pm 0.150$ $0.540 \pm 0.90$ 